\title{
PESQUISA BIBLIOGRÁFICA, PESQUISA BIBLIOMÉTRICA, ARTIGO DE REVISÃO E ENSAIO TEÓRICO EM ADMINISTRAÇÃO E CONTABILIDADE
}

\author{
BIBLIOGRAPHIC RESEARCH, BIBLIOMETRIC RESEARCH, REVIEW ARTICLE AND
}

THEORETICAL ESSAY IN ADMINISTRATION AND ACCOUNTING

Recebido em: 26/01/2018 • Aprovado em: 12/04/2018

Avaliado pelo sistema double blind review Editor Científico: Edson Sadao Iizuka DOI 10.13058/raep.2018.v19n2.970

\section{SANDRO VIEIRASOARES sandrovs@usp.br \\ ICARO ROBERTO AZEVEDO PICOLLI \\ JACIR LEONIR CASAGRANDE}

\author{
Universidade do Sul de Santa Catarina
}

\begin{abstract}
RESUMO
O objetivo do presente trabalho consistiu em caracterizar a pesquisa bibliográfica, a pesquisa bibliométrica, $o$ artigo de revisão e o ensaio teórico. Para tanto, desenvolveu-se uma análise de conteúdo acerca dos conceitos presentes nos livros-texto de metodologia, além de fontes complementares, buscando identificar o que são, que objetivo têm e de que formas se apresentam esses quatro tipos de textos. Nesse sentido, verificou-se, na literatura, que há características partilhadas nesses diferentes tipos de textos, o que os tornam iguais, bem como que há características que os distinguem, tornando-os únicos. A pesquisa bibliográfica apresenta-se, na literatura, como mais flexível, podendo, inclusive, ser apenas parte da pesquisa empírica, bem como ser apresentada na forma de um capítulo de tese ou dissertação. A pesquisa bibliométrica precisa, necessariamente, contemplar uma etapa de análise quantitativa de dados. $\mathrm{O}$ artigo de revisão tem como característica principal a sistematicidade com a qual o material bibliográfico foi coletado e analisado. Tanto a pesquisa bibliográfica quanto o artigo de revisão, usualmente, são apresentados conforme estrutura de pesquisa empírica. O ensaio, por sua vez, distancia-se dos outros três, pois independe de evidências empíricas, de análises quantitativas, de sistematicidade em sua construção por possuir uma estrutura amorfa. A qualidade do ensaio decorre da originalidade e do ineditismo de sua proposição.
\end{abstract}

Palavras-chave: Pesquisa bibliográfica. Pesquisa bibliométrica. Artigo de revisão. Ensaio teórico.

\begin{abstract}
The aim of this research is to characterize bibliographic research, bibliometric research, the review article and theoretical essay. For that, we developed a broad content analysis about the concepts present in methodology textbooks as well as in complementary sources, seeking to identify what they are, what are their purposes and the forms in which the four types of texts are presented. It was verified that the literature points out that, in fact, there are characteristics shared by the different types of texts, as well as characteristics that make them unique. Bibliographic research is presented in the literature as more flexible and may even be only a part of an empirical research, being presented in the form of a thesis or dissertation chapter. Bibliometric research must necessarily include a step of quantitative data analysis. The main feature of the review article is the systematicity with which the bibliographic material is collected and analyzed. Both the bibliographic research and the review article sare usually presented according to the empirical research structure adopted. The essay, in its turn, distances itself from the three other types of texts as it does not require empirical evidence, quantitative analyzes, and systematicity in its construction, and because it has an amorphous structure. The quality of the essay stems from the originality and the novelty of its proposition.

Keywords: Bibliographic research. Bibliometric research. Review article. Theoretical essay.
\end{abstract}




\section{INTRODUÇÃO}

Existe uma variedade de tipos de comunicação científica na ciência. O Manual de Publicação da American Psychological Association (2012) reconhece que, em ciências comportamentais e sociais, os tipos de artigos são os estudos empíricos, as revisões de literatura, os artigos teóricos, os artigos metodológicos e os estudos de caso.

O Encontro da Associação Nacional de Pós-Graduação e Pesquisa em Administração - EnANPAD (2017), maior evento científico da área de negócios no Brasil, aceita quatro tipos de manuscritos científicos: teórico-empíricos, ensaios teóricos, casos para ensino e artigos tecnológicos. Os Seminários em Administração - Semead (2017), outro evento prestigiado pela comunidade científica de Administração, elenca três tipos de trabalhos que podem ser submetidos: artigos científicos, relatos tecnológicos e casos de ensino.

Em cada área da ciência, determinados estilos literários têm mais popularidade que outros, sendo que, na área de Administração, Ciências Contábeis e Turismo, os estudos empíricos predominam.

Embora a correta classificação dos artigos produzidos pelos pesquisadores não afete as suas conclusões, a incorreta classificação desses mesmos artigos pode afetar a forma como são avaliados pelos pares. De fato, avaliar um estudo empírico com a régua de um ensaio teórico é inadequado e, certamente, contraproducente.

Cada tipo de texto científico tem um propósito específico do qual se espera contribuições com características próprias. Nesse sentido, um fenômeno está acontecendo nas áreas de Administração, Ciências Contábeis e Turismo, que é o debate acerca da pesquisa bibliográfica, da pesquisa bibliométrica, dos artigos de revisão e dos ensaios teóricos.

Desse modo, este artigo teve o objetivo de evidenciar os objetivos desses textos e explicitar as diferenças entre as características de cada um deles. Em sua apresentação, este artigo está dividido em: (i) introdução, composta pelo objetivo do estudo e o problema da pesquisa; (ii) revisão de literatura, onde se discute acerca dos diversos tipos de relatos de pesquisa; 
(iii) trajetória metodológica, em que se descreve o passo a passo da pesquisa; (iv) análise dos resultados, onde os conceitos são apresentados e discutidos, e (v) conclusão, em que se faz a síntese do trabalho e apontam-se sugestões para trabalhos futuros. 


\section{REVISÃO DE LITERATURA}

A comunicação científica reflete a variedade de tipos de pesquisa que pode ser feita nas Ciências Sociais Aplicadas. Em diferentes livros de metodologia de pesquisa, diversos autores apontam listas de opções de textos acadêmicos e suas características. $\mathrm{Na}$ área de Administração, Ciências Contábeis e Turismo, em que predomina o paradigma positivista, o texto acadêmico mais popular é o artigo empírico.

Nesse artigo, no entanto, aborda-se as opções elencadas pelo Manual de Publicação da Associação Americana de Psicologia - APA, que vem sendo adotado como norma de formatação de artigos em periódicos, como a Revista de Administração Contemporânea - RAC e em teses e dissertações de programas de pós-graduação de instituições tradicionais, como a Universidade de São Paulo (USP).

Segundo o Manual de Publicação da APA (2012, p. 26):

Estudos empíricos são relatos de pesquisa original. Eles incluem análises secundárias que testam hipóteses apresentando novas análises de dados não considerados ou abordados em relatos anteriores. Eles tipicamente consistem de seções distintas que refletem os estágios no processo de pesquisa e que aparecem na seguinte sequência:

- introdução: desenvolvimento do problema sob investigação, incluindo seus antecedentes históricos, e declaração do propósito da investigação;

- método: descrição dos procedimentos usados para conduzir a investigação;

- resultados: relato dos resultados e análises; e

- discussão: resumo, interpretação e implicação dos resultados.

Essa estrutura, segundo o Manual de Publicação da APA (2012), difere da estrutura mais comum encontrada nos eventos e periódicos brasileiros, que, usualmente, normatizam que os artigos empíricos submetidos sejam compostos de cinco seções: introdução, revisão de literatura, metodologia, resultados e conclusões.

$\mathrm{Na}$ seção introdução, também denominada considerações iniciais, abordam-se a contextualização do tema, o problema de pesquisa, o objeti- 
vo do trabalho, a justificativa e, em menos casos, a estrutura da divisão de seções do artigo. A seção de revisão de literatura, também chamada de fundamentação teórica, referencial teórico ou plataforma teórica, contempla conceitos e definições, legislação e normas, bem como todas as referências bibliográficas sobre a teoria (quando há uma), os resultados de pesquisas empíricas anteriores e até mesmo a discussão sobre as técnicas de análise utilizadas previamente. A seção de metodologia, também intitulada como procedimentos metodológicos, trajetória metodológica ou percurso metodológico, elenca, mais comumente, o tipo de pesquisa, a abordagem, a população e a amostra, a forma de coleta de dados, a técnica usada para análise e a interpretação dos dados, sendo ela o guia que conduz a pesquisa empírica. Na seção resultados, também designada por análise dos resultados, análise dos dados ou apresentação dos resultados, discutem-se os dados da pesquisa em si e comparativamente aos resultados de pesquisas anteriores, de modo a reafirmar ou discordar da literatura já existente. $\mathrm{Na}$ seção de conclusão, também nomeada de considerações finais ou conclusão e sugestões para pesquisas futuras, apresenta-se a resposta ao problema de pesquisa. Para isso, o autor sintetiza toda sua análise em uma conclusão, normalmente, exposta na forma afirmativa.

No entanto é muito comum que os autores apenas repitam resultados já discutidos na seção anterior, sem uma reflexão analítica do que significam esses resultados. Os eventos da Anpad (2017) utilizam uma ficha de avaliação para artigos chamados teórico-empíricos composta pelos seguintes critérios:

Clareza, pertinência e consecução dos objetivos

Qualidade da redação e organização do texto: (ortografia, gramática, clareza, objetividade e estrutura formal)

Originalidade do trabalho e relevância do tema

Qualidade da revisão de literatura

Consistência teórica do trabalho

Metodologia utilizada: (adequação e qualidade)

Análise de dados (ou informações) e resultados (articulação teórica e metodológica da interpretação) 
Conclusões: fundamento, coerência e alcance

Contribuição do trabalho para o conhecimento no Tema de Interesse

Contribuição teórica imediata ou potencial. (ENANPAD, 2017)

Pode-se observar que esses critérios remetem à avaliação das partes que dividem e estruturam os artigos empíricos e os conteúdos que elas devem conter.

O segundo tipo de texto científico, listado pelo Manual de Publicação da APA (2012), é a revisão de literatura, também conhecida como artigos de revisão, revisão sistemática da literatura ou revisão integrativa da literatura. De acordo com o Manual de Publicação da APA (2012, p. 26):

As revisões de literatura, incluindo sínteses de pesquisa e metanálises, são avaliações críticas de material que já foi publicado. Nas metanálises, os autores usam procedimentos quantitativos para combinar estatisticamente os resultados de estudos. Ao organizarem, integrarem e avaliarem material publicado anteriormente, os autores de revisões de literatura consideram o progresso da pesquisa para esclarecimento de um problema. Em certo sentido, as revisões de literatura são tutoriais uma vez que os autores:

- definem e esclarecem o problema;

- resumem as investigações anteriores para informar o leitor sobre o estado da pesquisa;

- identificam relações, contradições, lacunas e inconsistências na literatura; e

- sugerem o(s) próximo(s) passo(s) para a resolução do problema.

Os componentes das revisões de literatura podem ser organizados de diversas formas (p. ex: agrupando pesquisas com base na semelhança nos conceitos ou teorias de interesse, semelhanças metodológicas entre os estudos revisados, ou o desenvolvimento histórico da área).

Os artigos de revisão são bem menos comuns nas áreas de Administração, Ciências Contábeis e Turismo do que as pesquisas empíricas. Essa constatação pode indicar que os pesquisadores, na ausência do panorama que é traçado pelos artigos de revisão, podem estar fazendo pesquisas com objetivos já estudados, de forma que saturam determinados tipos de objetivos sem propor um avanço real ou significativo. 
O terceiro tipo de texto acadêmico, listado pelo Manual de Publicação da APA (2012, p. 26-27), é o artigo teórico:

[...] nos artigos teóricos os autores utilizam a literatura de pesquisa existente para aperfeiçoar a teoria. As revisões de literatura e os artigos teóricos, muitas vezes, têm estrutura semelhante, mas os artigos teóricos apresentam informações empíricas somente quando elas contribuem para uma questão teórica. Os autores de artigos teóricos traçam o desenvolvimento da teoria para expandir e refinar os constructos, apresentar uma nova teoria ou analisar uma teoria existente, apontando falhas ou demonstrando a vantagem de uma teoria sobre a outra. Neste tipo de artigo, os autores costumam examinar a consistência interna e validade externa de uma teoria. As seções de um artigo teórico, como as de uma revisão de literatura, podem variar quanto à ordem de seu conteúdo.

Assim como os artigos de revisão, os artigos teóricos são muito menos populares do que os artigos empíricos, pois demandam do autor algumas habilidades, como alta capacidade analítica, conhecimento amplo da literatura e da epistemologia e ampla experiência na área. Neles, o autor precisa expor uma perspectiva crítica e uma contribuição pessoal na discussão da problemática tratada.

O quarto tipo de texto acadêmico, segundo o Manual de Publicação da APA (2012, p. 27), é o artigo metodológico:

Os artigos metodológicos apresentam novas abordagens metodológicas, modificações dos métodos existentes ou discussões de abordagens quantitativas e analítica de dados para a comunidade de pesquisadores. Estes artigos se concentram em abordagens metodológicas ou analíticas de dados e introduzem dados empíricos somente enquanto ilustrações da abordagem. Os artigos metodológicos são apresentados em um nível que os torna acessíveis ao pesquisador versado e fornecem detalhes suficientes para que pesquisadores avaliem a aplicabilidade da metodologia a seu problema de pesquisa. Além disso, o artigo permite que o leitor compare os métodos propostos com aqueles que estão em uso corrente e implemente os métodos propostos. Nos artigos metodológicos, materiais altamente técnicos (p. ex., derivações, provas, detalhes de simulações) devem ser apre- 
sentados em apêndices ou como materiais suplementares para melhorar a legibilidade geral do artigo.

Esse tipo de artigo é pouco frequente na área de Administração, Ciências Contábeis e Turismo, embora, quando aparece, costuma não só ser muito citado pela área, mas, também, por áreas adjacentes.

Conforme o Manual de Publicação da APA (2012, p. 27), o último dos tipos de texto científico é o estudo de caso:

Estudos de caso são relatos de materiais de casos obtidos mediante o trabalho com um indivíduo, um grupo, uma comunidade ou uma organização. Os estudos de caso ilustram um problema; indicam uma forma de resolver um problema; e/ou elucidam pesquisas necessárias, aplicações clínicas ou assuntos teóricos. Ao redigir estudos de caso, os autores consideram cuidadosamente o equilíbrio entre prover material ilustrativo importante e usar material de caso confidencial com responsabilidade.

Deve-se considerar que estudos de caso não é o mesmo que casos de estudo. Uma literatura específica sobre o uso de estudos de caso em suas dimensões de contribuição e rigor metodológico na área de Administração e Contabilidade no Brasil é composta pelos trabalhos de Pozzebon e Freitas (1998), Alves-Mazzotti (2006), Oliveira, Maçada e Goldoni (2009), Cesar, Antunes e Vidal (2010) e Campos, Cunha e Barbosa Neto (2015). 


\section{TRAJETÓRIA METODOLÓGICA}

A trajetória metodológica desta pesquisa teve início com a definição dos termos a serem buscados nos livros-texto de metodologia. A escolha desses termos deu-se após a revisão da literatura sobre o tema, principalmente, baseando-se no Manual de Publicação da APA (2012). Assim, os termos escolhidos para a definição de pesquisa bibliográfica foram: "bibliográfica" e "bibliográfico"; para pesquisa bibliométrica: "bibliométrica", bibliométrico" e "bibliometria"; para o artigo de revisão: "revisão", "revisão sistemática" e "revisão integrativa"; e, para ensaio, "ensaio".

Posteriormente, definidas essas palavras-chave, procedeu-se à busca no acervo de três bibliotecas: duas virtuais e uma física. A primeira biblioteca consultada foi a Biblioteca Virtual Universitária (Pearson), que recuperou apenas um conceito de um só livro, pouco contribuindo para o resultado final da pesquisa. (BIBLIOTECA VIRTUAL UNIVERSITÁRIA, 2017). A segunda biblioteca virtual consultada foi a Minha Biblioteca, que é um consórcio formado pelas editoras Grupo A, Grupo Gen-Atlas, Manole e Saraiva, para disponibilizar e-books aos estudantes de instituições de ensino e que abrange 8.843 livros (MINHA BIBLIOTECA, 2017). A maior parte dos conceitos identificados foi encontrada no acervo dessa biblioteca. Por fim, com a finalidade de complementar a busca com títulos de obras não disponíveis em versão $e$-book, procedeu-se a uma busca no acervo físico (impresso) de uma biblioteca universitária.

A busca dos conceitos foi realizada nos meses de setembro e outubro de 2017 e os resultados foram analisados de outubro de 2017 a janeiro de 2018.

A análise realizada iniciou-se com as obras que continham mais conceitos, os quais foram explorados de forma a sintetizar as características dos tipos de textos desta pesquisa. Aos primeiros conceitos analisados e sintetizados, foram agregadas características dos demais autores quando possível. Por fim, discutiram-se questões que caracterizam a forma como os quatro tipos de texto são, usualmente, expostos. 


\section{ANÁLISE DOS RESULTADOS}

Nesta seção, discutem-se as características de conceito, objetivo e forma de apresentação dos quatro tipos de textos, já definidos e referidos, isto é: pesquisa bibliográfica, pesquisa bibliométrica, artigo de revisão e ensaio teórico.

\section{Pesquisa Bibliográfica}

Em busca realizada na Scielo, pelo termo "pesquisa bibliográfica" no título, foram recuperados 10 resultados (SCIELO, 2017). Já na busca realizada na Spell, com o termo "bibliográfica", que engloba as expressões "análise bibliográfica" e "pesquisa bibliográfica", foram recuperados 40 resultados, e com o termo "bibliográfico", que engloba expressões como "levantamento bibliográfico", "estudo bibliográfico", "portfólio bibliográfico", recuperou 16 resultados (SPELL, 2017).

Para Martins e Theóphilo (2016, p. 52), a pesquisa bibliográfica:

Trata-se de estratégia de pesquisa necessária para a condução de qualquer pesquisa científica. Uma pesquisa bibliográfica procura explicar e discutir um assunto, tema ou problema com base em referências publicadas em livros, periódicos, revistas, enciclopédias, dicionários, jornais, sites, CDs, anais de congressos etc. Busca conhecer, analisar e explicar contribuições sobre determinado assunto, tema ou problema. A pesquisa bibliográfica é um excelente meio de formação científica quando realizada independentemente - análise teórica - ou como parte indispensável de qualquer trabalho científico, visando à construção da plataforma teórica do estudo.

Para Michel (2015), a pesquisa bibliográfica pode ser uma pesquisa em si ou apenas uma fase de uma pesquisa descritiva ou experimental, no que concorda com Martins e Theóphilo (2016). A autora, no entanto, acresce que a pesquisa bibliográfica constitui-se no embasamento necessário e básico para a realização de estudos monográficos, ressalvando que o levantamento bibliográfico é a essência do estudo exploratório, devendo ser 
acompanhado de anotações, registros, notas de aulas, além de apontamentos que se relacionem com o tema de interesse, de forma a constituir-se numa memória importante para o registro e a redação do trabalho. A autora expõe, ainda, que a pesquisa bibliográfica em si dispensa a elaboração de hipóteses, mas destaca que ela pode ser orientada pela hipótese de pesquisa experimental.

Por sua vez, Gil (2017) concorda com Martins e Theóphilo (2016) ao argumentar que a pesquisa bibliográfica constitui uma etapa preliminar de praticamente toda a pesquisa acadêmica, e acrescenta que quase toda tese ou dissertação desenvolvida, atualmente, contém um capítulo ou seção dedicado à revisão bibliográfica, com o duplo propósito de fornecer fundamentação teórica ao trabalho, bem como identificar o estágio atual do conhecimento de determinado tema. O mesmo autor alerta que a pesquisa bibliográfica apresenta como vantagem o fato de que o pesquisador pode ter acesso a uma gama de fenômenos muito mais ampla do que aquela que ele poderia pesquisar diretamente, alertando, todavia, que os dados consultados podem conter erros, e que a pesquisa bibliográfica pode reproduzir ou mesmo ampliar esses erros se não houver um processo cuidadoso de verificação das fontes, na busca de incoerências e contradições.

Em algumas áreas do conhecimento, como Direito, Filosofia e Literatura, a maioria das pesquisas baseia-se, mormente, em fontes bibliográficas, assim como há pesquisas que elucubram sobre o pensamento de determinado autor ou os diversos pontos de vista a respeito de um assunto específico (GIL, 2017). Em Administração e Contabilidade, áreas de pesquisa como contabilidade tributária, comércio internacional e administração pública têm facetas que as assemelham com pesquisa em Direito e podem utilizar-se de pesquisa bibliográfica.

Para Andrade (2010, p. 73), as etapas da pesquisa bibliográfica são apresentadas na Figura 1: 
Figura 1 Etapas da pesquisa bibliográfica

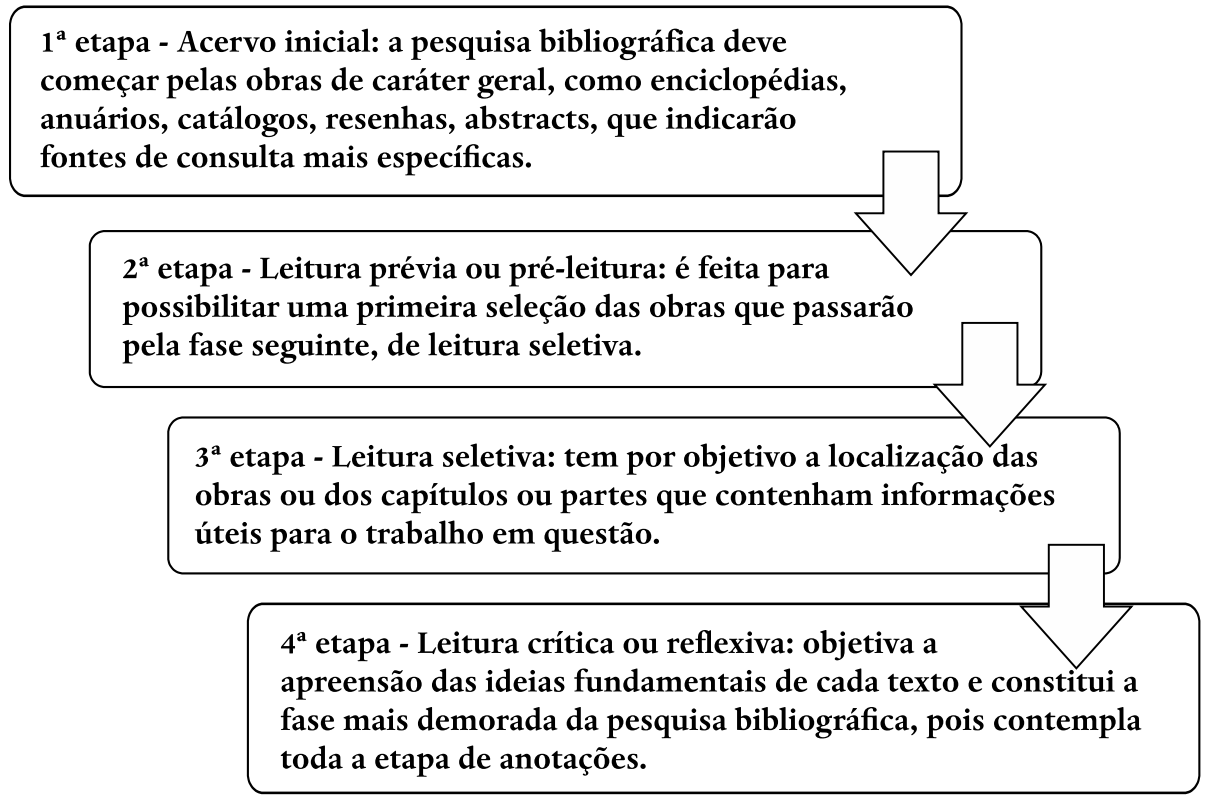

Fonte: Adaptado de Andrade (2010, p.).

A primeira etapa consiste em um levantamento de referências sobre o assunto-objeto de pesquisa, devendo-se atentar para a cobertura, a qualidade e a relevância das referências. A cobertura deve ser ampla, contemplando trabalhos recentes e antigos, nacionais e internacionais, sempre que possível. A qualidade diz respeito às fontes consultadas, de modo que artigos de periódicos devem prevalecer sobre artigos de anais de eventos; que teses prevaleçam sobre dissertações e monografias de graduação ou especialização; e que livros técnicos prevaleçam sobre os didáticos, embora essas orientações possam ser flexibilizadas em função dos temas estudados. A relevância deriva da necessidade de não se deixar de fora nenhuma referência relevante, tampouco incluir referências que não o sejam.

De posse desse conjunto inicial de referências, deve-se proceder a uma pré-leitura, que eliminará obras que não condizem com o objetivo do estudo. As obras restantes passarão pela fase de leitura seletiva, que eliminará as referências que não contenham informação útil para a pesquisa. Por 
fim, na quarta etapa, procede-se a uma leitura crítica, feita em profundidade, para separar aquilo que é indispensável daquilo que é complementar ou desnecessário.

Nessa fase, também, são feitos fichamentos e anotações, que auxiliarão na redação final da pesquisa. Antigamente, essa etapa incluía fichamentos escritos manualmente, bem como se fazia a colagem de post-its em livros impressos. Com os avanços tecnológicos em informática, cada vez mais são utilizados recursos eletrônicos como softwares de gerenciamento de referências, como, por exemplo, Endnote e Mendeley, softwares de edição de arquivos em Portable Document Format - pdf, como o Adobe Acrobat, softwares de análise de dados qualitativos, como Atlas.TI ou NVivo, e mesmo mecanismos de anotações em arquivos, como o disponibilizado pela biblioteca virtual Minha Biblioteca, pelo Kindle ou por outros tablets.

Para Andrade (2010), as anotações devem ser feitas somente após a compreensão e apreensão das ideias contidas no texto, e compreendem resumos, análises, transcrições de trechos, interpretações, esquemas, ideias fundamentais expostas pelos autores, tipos de raciocínio, frases que concorrem para a redação da introdução ou da conclusão, palavras-chave ou mesmo, simplesmente, trechos grifados.

A pesquisa bibliográfica, na academia, encontra espaço, principalmente, no âmbito da graduação, para fins de trabalhos de conclusão de cursos; e, em pós-graduação, tão somente em pesquisas exploratórias. A maior parte dos pesquisadores opta por pesquisas que contemplam características de maior rigor metodológico, como os artigos de revisão, com a intenção de evitar vieses de amostra da literatura abordada.

As pesquisas bibliográficas assumem dois formatos principais: capítulo ou artigo completo. Quando a pesquisa bibliográfica é realizada com o propósito de fundamentar uma pesquisa empírica, normalmente, ela é apresentada como um capítulo chamado "revisão de literatura", "fundamentação teórica" ou "referencial teórico". Quando a pesquisa bibliográfica é realizada com o propósito em si mesma, ela assume o formato de um artigo empírico, sendo composta, geralmente, por seções de introdução, que pode ou não conter hipóteses, revisão de literatura, metodologia, resultados e conclusões. 


\section{PESQUISA BIBLIOMÉTRICA}

Sobre pesquisa bibliométrica, em busca realizada na Scielo, pelo termo "bibliométrica" no título, contemplando "pesquisa bibliométrica", como também "análise bibliométrica", foram recuperados oito resultados (SCIELO, 2017). A pesquisa na Spell com o termo "bibliométrico" no campo título obteve 107 resultados, e com o termo "bibliométrica" foram 102 resultados (SPELL, 2017).

No Quadro 1, destacam-se alguns dos principais indicadores bibliométricos, segundo Okubo (1997) e Splitter, Rosa e Borba (2012):

Quadro 1 Indicadores bibliométricos

\section{INDICADOR}

Lei de Lotka

Lei de Bradford

Lei de Zipf

Número de publicações por autor, revista, instituição ou tema

Número de coautores / colaboradores

Copublicações: publicação com autores de diferentes países, instituições

\section{Conceito}

Investiga as distribuições de frequência da autoria de artigos de determinado tema/área. Investiga as distribuições de frequência do número de artigos publicados por periódicos de determinado tema/área. Investiga as distribuições de frequência do vocabulário de textos de determinado tema/área. Investiga o volume de publicações de autores, periódicos, instituições ou temas de determinada área. Investiga a dinâmica do volume de pesquisa realizada de forma colaborativa, seja entre pesquisas individuais ou em grupo, ou nacionais e internacionais.

Investiga a cooperação entre representantes de entidades e países, em pesquisas conjuntas, com a finalidade de criar uma matriz que evidencie os principais parceiros e forneça a descrição da rede científica. 
Investiga o impacto dos artigos, dos periódicos

Número de citações e dos pesquisadores em função do número de citações.

Índice de afinidade

Investiga a taxa relativa de trocas científicas (entre países, instituições) por meio de citações.

Laços científicos

Investiga e mensura a influência de redes entre diferentes comunidades científicas.

Investiga o número de vezes que dois ou mais

Cocitações artigos são citados, simultaneamente, num mesmo artigo.

Fonte: Adaptado de Okubo (1997) e Splitter, Rosa e Borba (2012, p.).

No Brasil, os indicadores mais populares em artigos bibliométricos são baseados em contagem de número de artigos, número de revistas, número de autores, número de autorias, número de instituições ou número de citações. As distribuições de frequência usadas nas Leis de Lotka, de Bradford e Zipf são bem menos utilizadas nos artigos bibliométricos. Os demais indicadores, como índice de afinidade, laços científicos e cocitações, por sua vez, raramente são utilizados (SPLITTER; ROSA; BORBA, 2012).

Tradicionalmente, os estudos bibliométricos são desenvolvidos a partir das informações obtidas de grandes bases de dados como Web of Science e Scopus. A ausência de indexação de revistas brasileiras da área de Administração, Ciências Contábeis e Turismo, na coleção das grandes bases de dados, desestimulou a criação de uma cultura de utilização de indicadores bibliométricos mais sofisticados, por parte da comunidade científica brasileira, até o início do século XXI.

No início do século XXI, ocorreram dois fenômenos que estão impactando na forma como os pesquisadores calculam e utilizam indicadores bibliométricos. O primeiro deles foi o desenvolvimento do buscador aberto Google Scholar, a partir de 2004, pela Google e seu concorrente, o Microsoft Academic Search, criado em 2006 e relançado como Microsoft Academic, em 2016. Baseado no Google Scholar, também foi criado o sof- 
tware gratuito Harzing's Publish or Perish, pela pesquisadora australiana Anne-Will Harzing.

Diversos artigos brasileiros têm-se utilizado desses recursos eletrônicos para o desenvolvimento de pesquisas com indicadores bibliométricos, tais como as de Souza, Ensslin e Ensslin (2012), Aragão, Oliveira e Lima (2014), Soares e Casa Nova (2016, 2017), Soares e Lima Filho (2017).

O segundo fenômeno que está impactando a dinâmica de utilização de indicadores bibliométricos é a indexação de revistas brasileiras nas grandes bases de dados internacionais, que vem ocorrendo de forma individual ou coletiva, por exemplo, revistas como a Revista Brasileira de Gestão de Negócios e a Custos e @gronegócio online, que conseguiram indexação no Web of Science por iniciativa individual; ou, de forma coletiva, como ocorreu com a indexação, em 2014, da coleção Scielo na Web of Science, por meio do acordo firmado pela Fapesp com a Thomson Reuters (PACKER, 2014).

A pesquisa bibliométrica apresenta a mesma estrutura de um artigo empírico, sendo composta pelas seções: introdução, revisão de literatura, metodologia, resultados e conclusões. As seções de introdução, revisão de literatura e conclusões dos artigos bibliométricos guardam muita semelhança com o que se observa nos artigos empíricos, visto que elas também contêm elementos de contextualização do tema, desenvolvimento histórico, problema de pesquisa, objetivo de pesquisa, justificativa, pesquisas anteriores, fechamento e resultados, limitações, contribuição para o meio acadêmico e sugestões para pesquisas futuras.

Já as seções de metodologia e resultados devem conter uma descrição detalhada das bases de dados, dos bancos de teses e dissertações e do conjunto de anais de eventos consultados, assim como a sua abrangência e cobertura; as justificativas para a escolha dessas bases, devendo justificar também a escolha do recorte temporal, se houver. A inclusão desses elementos acerca da cobertura do acervo de referências consultadas na pesquisa bibliométrica não é mandatória, mas é altamente recomendada para sustentar a legitimidade da pesquisa, bem como deve ser explicitado, para os demais pesquisadores interessados no tema, o possível viés derivado da 
arbitrariedade na escolha limitada de fontes de informação, que pode, inclusive, ser objeto de pesquisas futuras.

Há que se fazer uma ressalva a respeito das limitações acerca da cobertura de acervo de obras nos estudos bibliométricos brasileiros, como, por exemplo, na escolha de revistas de Administração pertencentes aos estratos A1 a B1 do Qualis da Capes. Esse critério, embora seja comumente utilizado na área, guarda uma armadilha implícita, pois, embora, normalmente, ele seja estabelecido em prol da exequibilidade da pesquisa, com a justificativa de que as revistas pertencentes a esses estratos são caracterizadas por melhor qualidade que as demais, elas podem não cobrir assuntos, metodologias ou amostras não pertencentes ao mainstream. Segundo Soares (2017), existe uma associação estatisticamente significativa entre determinadas linhas de pesquisa e Qualis, e entre abordagem da análise de dados e Qualis.

$\mathrm{Na}$ análise dos resultados, pressupõe-se que haja uma análise quantitativa dos dados, visto que a própria origem do termo bibliometria deu-se pela junção do radical biblion, do grego, livro, com o sufixo metria, no grego, mensuração. A ausência da análise quantitativa descaracteriza a pesquisa bibliométrica, que pode, dependendo do conteúdo, ser classificada como pesquisa bibliográfica. 


\section{ARTIGO DE REVISÃO}

Em consulta à base de dados Scielo, pelo termo "artigo de revisão", no campo título, foram recuperados 42 resultados. (SCIELO, 2017). A pesquisa na Spell, pelo termo "artigo de revisão", no campo título, apresentou zero resultado (SPELL, 2017).

Conforme Procianoy (2013, p. 189), "chamamos de revisão sistemática a pesquisa e a avaliação crítica de resultados de trabalhos baseados em evidência. Esta revisão emprega um protocolo específico para determinar os estudos que farão parte da mesma (faz-se uma análise qualitativa)". Já para Nogueira (2015), os artigos de revisão são trabalhos publicados pelos maiores especialistas de uma determinada área, que buscam avaliar, criteriosamente, o conjunto de pesquisas produzidas e separar, por assim dizer, o joio do trigo.

Esse tipo de artigo é muito popular no exterior, nas mais diversas áreas, inclusive, em Administração e Contabilidade, em que há um periódico, o Journal of Accounting Literature, específico para esse tipo de texto. No Brasil, os artigos de revisão são mais restritos às Ciências Biológicas e da Saúde, áreas em que são relativamente numerosos, por constituírem a forma como os médicos contornam o desafio de navegar entre os muitos resultados contraditórios, que se acumulam na literatura (NOGUEIRA, 2015).

Para Procianoy (2013, p. 189), "o objetivo da metanálise é integrar os resultados de estudos individuais (considerados passíveis de serem combinados) para fornecer uma estimativa de resultado [...]" e que "por sua característica, a metanálise permite diminuir custos e tempo na realização de pesquisas adicionais, bem como buscar uma melhor evidência diante dos estudos com resultados contraditórios ou não conclusivos (estudos com amostras pequenas)".

Botelho, Cunha e Macedo (2011) classificam os artigos de revisão em quatro tipos: revisão sistemática, metanálise, revisão qualitativa e revisão integrativa, que se dividem conforme disposto a seguir, no Quadro 2. 
Quadro 2 Tipos de artigos de revisão

\section{Tipo}

Revisão sistemática hipóteses idênticas ou relativas. Um sumário de pesquisas passadas, que usa técnicas de estatísticas para transformar descobertas de Metanálise estudos com hipóteses idênticas
ou relativas em uma medida comum e que calcula o efeito total, a magnitude do efeito e os efeitos de subamostras.

Revisão qualitativa

Um sumário de pesquisas passadas, que combina as descobertas de múltiplos estudos qualitativos.

$\begin{array}{ll}\text { Revisão } & \begin{array}{l}\text { Um sumário da literatura, num } \\ \text { conceito específico ou numa área } \\ \text { de conteúdo, em que a pesquisa é }\end{array} \\ \text { integrativa } & \begin{array}{l}\text { sumariada (resumida), analisada e } \\ \text { as conclusões totais são extraídas. }\end{array}\end{array}$

Estimar o efeito de intervenções ou de relacionamentos. evidência concernente a um problema clínico específico.

Propósito

Sumariar (resumir)

\section{Informar pesquisas ou} práticas pela sumarização (resumo) de processos ou experiências.

Revisar métodos, teorias, e/ou estudos empíricos sobre um tópico particular.

Fonte: Adaptado de Botelho, Cunha e Macedo (2011, p.).

Os mesmos autores, Botelho, Cunha e Macedo (2011), propõem um protocolo para o desenvolvimento de artigo de revisão de seis etapas: 1 . Identificação do tema e seleção da questão de pesquisa; 2. Estabelecimento dos critérios de inclusão e exclusão; 3 . Identificação dos estudos pré-selecionados e selecionados; 4. Categorização dos estudos selecionados; 5 . Análise e interpretação dos resultados; e 6. Apresentação da revisão/síntese do conhecimento. 
Por sua vez, Procianoy (2013) sugere um protocolo específico para o desenvolvimento de metanálise em oito etapas, que compreendem: 1. Pesquisa de todos os títulos e resumos sobre um tópico; 2. Seleção dos estudos que permanecem na análise; 3 . Tabulação das características dos estudos; 4. Separação dos estudos por suas qualidades; 5 . Análise dos dados; 6 . Teste de sensibilidade para verificar homogeneidade e viés/tendenciosidade; 7. Descrição, e 8. Discussão dos resultados.

O elemento que melhor caracteriza, especifica e diferencia o artigo de revisão da pesquisa bibliográfica genérica é a sistematicidade com a qual se procede a busca de material bibliográfico a ser analisado. Nesse sentido, existem diversos protocolos que orientam a formalização dessa busca, como o Proknow-C, knowledge development process-constructivist (ENSSLIN et al., 2010), o SystematicSearchFlow - SSF (FERENHOF; FERNANDES, 2016) e o Scientometric and Systematic Yielding Mapping Process - SYSMAP (VAZ; MALDONADO, 2017). A escolha de um desses protocolos deve ser feita com muito critério, e sua aplicação precisa ser desenvolvida com rigor, de modo que outro pesquisador possa seguir os mesmos passos e encontrar os mesmos resultados ou, pelo menos, resultados bastante próximos, à guisa de pesquisas empíricas.

É importante destacar que alguns dos protocolos de artigos de revisão estabelecem, inclusive, as bases de dados que devem ser consultadas, como, por exemplo, Scopus ou Web of Science, que determinam que as palavras-chave consultadas devem ser em inglês e exigem que as fontes bibliográficas consultadas se limitem a artigos de periódicos. No entanto o bom senso do pesquisador deve prevalecer quando este detectar que há maior ganho para a pesquisa se usar bases brasileiras, como a Scielo e a Spell, adotando palavras-chave em idioma português e consulta a bancos de teses e dissertação e a anais de eventos.

Esse cuidado é importante porque, ao artigo de revisão, aplica-se a máxima, reproduzida anteriormente, sobre pesquisa bibliográfica: de não se deixar de fora nenhuma referência relevante, tampouco incluir referências que não o sejam. A exclusão de bancos de teses e dissertações pode eliminar resultados de pesquisas importantes, já que podem levar muito 
tempo para serem captadas em bases de dados, pois é sabido que o processo editorial de avaliação por pares pode levar de dias a anos. Do mesmo modo, é sabido que há temáticas que são aceitas em eventos, e não o são em periódicos, na mesma proporção, de modo que o gargalo gerado de uma etapa para a outra também evitaria que esses artigos fossem captados nas bases de dados. Para exemplificar, a área de Contabilidade Tributária é uma em que se observa a ocorrência de artigos que são aceitos e apresentados em eventos, mas que se tornam desatualizados durante o demorado processo editorial e acabam por ser recusados.

Pela observação dos aspectos analisados, resta avaliar a estrutura pela qual uma pesquisa de revisão deve ser reportada na forma de artigo. A estrutura mais usual é tratar o artigo de revisão como um artigo empírico, iniciando com uma introdução, que contém uma contextualização e uma questão de pesquisa; uma seção de revisão de literatura, mormente para apresentar os termos e conceitos relacionados à pesquisa, e, menos usualmente, os resultados de pesquisas anteriores; uma seção de metodologia, que descreve cuidadosa e detalhadamente o passo a passo das etapas do protocolo escolhido, bem como as escolhas metodológicas do autor; uma seção de análise de resultados, em que se faz a comparação, o cruzamento e a síntese das pesquisas que compõem a amostra; e, por fim, uma seção de conclusão, na qual se responde à questão de pesquisa.

Essa estrutura, contudo, não deve ser encarada como uma fórmula engessada, ao contrário, deve moldar-se ao conteúdo a ser reportado, com isso, visando à legibilidade e à compreensão por parte do leitor. 


\section{ENSAIO}

Na Scielo, em busca usando o termo "ensaio teórico" nos títulos, foram recuperados 11 resultados (SCIELO, 2017). A pesquisa realizada na Spell, com o mesmo termo "ensaio teórico" no campo título, resultou em 21 resultados (SPELL, 2017).

A característica mais elementar do ensaio é a originalidade e seu entendimento está relacionado à concepção de novidade. O ensaio precisa ter algum elemento de originalidade, associado ao ineditismo. Assim, precisa de algo incomum, nunca visto, publicado ou impresso. A originalidade pode estar na argumentação, na escolha do objeto de análise, no recorte dado à análise, na abordagem epistemológica, na subversão da racionalidade dominante, relacionada ao tema (MENEGHETTI, 2011a). Para Michel (2015), o ensaio acadêmico defende uma ideia ou visão original de algo, sendo que não precisa ser original na sua concepção, podendo apresentar um novo viés, uma nova abordagem, nova característica, qualidade ou problema do objeto de interesse.

No entanto, por essa característica, não se deve confundir o ensaio com um trabalho de estado da arte, que Rother (2007) denomina de revisão narrativa de literatura, e que, segundo Bertero (2011), é aquele em que são criticamente apresentadas as posições de vários autores, escolas ou grupos de analistas que se ocuparam do tema.

O ensaio é muito utilizado na área das Ciências Sociais, também nas áreas de Física, Literatura, Filosofia, Química e Biologia; e tem como benefício a capacidade de quebrar a lógica esquemática e sistemática da ciência tradicional, sobretudo, de natureza positivista (MENEGHETTI, 2011a).

O ensaio não requer a comprovação empírica, mesmo que ela possa apresentar-se como elemento de confirmação de pressupostos. No ensaio, os procedimentos de coleta e evidenciação do mundo empírico não são o centro de sustentação da sua forma. Todavia não se pode negar a importância da evidência empírica como proposição elementar da produção de conhecimento (BERTERO, 2011; MENEGHETTI, 2011a). O EnANPAD 
(2017) utiliza uma ficha de avaliação para a modalidade ensaio teórico composta pelos critérios a seguir:

Clareza, pertinência e consecução dos objetivos

Qualidade da redação e organização do texto: (ortografia, gramática, clareza, objetividade e estrutura formal)

Originalidade do trabalho e relevância do tema

Qualidade da revisão de literatura

Consistência teórica do trabalho

Conclusões: fundamento, coerência e alcance

Contribuição do trabalho para o conhecimento no Tema de Interesse

Contribuição teórica imediata ou potencial. (ENANPAD, 2017)

Nota-se que a ficha de avaliação do ensaio teórico difere da ficha de avaliação do artigo empírico pela ausência dos critérios "Metodologia utilizada: (adequação e qualidade)" e "Análise de dados (ou informações) e resultados (articulação teórica e metodológica da interpretação)", diferença esta que vai ao encontro do posicionamento de Bertero (2011) e Meneghetti (2011a) no sentido de que o ensaio prescinde de comprovação empírica.

$\mathrm{Na}$ área acadêmica, os ensaios tornaram-se formas facilitadas de produção considerada científica, sobretudo, nas áreas das humanidades ou das ciências sociais aplicadas, incluindo administração, teoria das organizações, etc. Meneghetti (2011a), contudo, alerta que muitos indivíduos apelam para o ensaio por parecer que nele cabe tudo. Sabe-se, porém, tratar-se isso de um engano, pois, conforme leciona Bertero (2011), a produção de um ensaio é fundamentalmente difícil, ademais não há como salvar um mau ensaio. E esse autor é ainda mais incisivo acerca da capacidade de produção de um ensaio ao afirmar que:

Dos diversos dons que possamos receber, o de ser teórico é muito raro. Por isso a maioria da produção científica não é nem poderia ser teórica. Poucos são suficientemente dotados para gerar teorias sob a forma de ensaios teóricos. Diria, com alguma crueldade, que a maioria de nós completa sua jornada neste planeta sem jamais ter tido uma ideia própria 
ou original. Muitas vezes, se consegue grande sucesso, particularmente na academia, repetindo, não necessariamente com brilhantismo e capacidade, as ideias e teorias dos outros. (BERTERO, 2011, p. 342).

Diferente do método tradicional da ciência, em que a forma é considerada mais importante do que o conteúdo, o ensaio requer sujeitos, ensaísta e leitor capazes de avaliarem que a compreensão da realidade também ocorre de outras formas (MENEGHETTI, 2011a). Para o autor, não são somente os pares de uma mesma área de conhecimento ou da mesma especialidade que reconhecem se um ensaio é digno de validade ou legitimidade; é o conjunto amplo de indivíduos e coletivos que lhe dão legitimidade, quando o reconhecem como influente e importante no processo de reflexão sobre o que ele se propõe a pensar.

Michel (2015) ensina que o ensaio acadêmico tem características do texto científico, como o caráter dissertativo, com discussão teórica, no propósito de defender, racional e logicamente, um ponto de vista ou uma ideia, sem proposta de aprofundamento ou pretensão de esgotamento do assunto. Para a autora, o ensaio não significa mera narrativa ou descrição de fatos, ou características, ou postulados doutrinais.

Ainda, segundo Michel (2015), o ensaio deve basear-se em autores que escreveram sobre o assunto, utilizando argumentos e contra-argumentos em favor das ideias propostas, buscando originalidade nesses argumentos. O ensaísta necessita ter competência para expor e defender ideias; razoabilidade para tratar a dialética necessária à discussão; bom senso e autocontrole para não se deixar levar por motivos apaixonados e de caráter emocional; e, principalmente, necessita ter muita competência e capacidade de persuasão. Para Bertero (2011), a qualidade do ensaio depende, diretamente, da bagagem de cultura e conhecimentos e da reflexão acumulada do autor sobre o tema que escolheu abordar. Tudo isso, certamente, requer do seu autor maturidade sobre o tema (MENEGHETTI, 2011a).

Sobre o uso do ensaio na área de Administração, Meneghetti (2011a, p. 330-331) conclui que: 
No desenvolvimento do ensaio, são geradas as próprias conclusões para as reflexões anunciadas inicialmente em forma de questionamentos. Assim, esta parte do ensaio não é uma conclusão no sentido tradicional; apenas direciona a reflexão para pensar a realidade do ensaio como forma na administração. Ensaio não é estudo teórico, baseado em revisões teóricas que, posteriormente, vão amparar pesquisas empíricas ou reflexões conceituais, formatadas dentro da divisão clássica da ciência. Existe equívoco, quando é atribuído o nome de ensaio-teórico para estudos que se caracterizam como estudos teóricos. Este equívoco tornou-se quase regra, chegando a ser institucionalizado nos programas de pós-graduação e pesquisa em administração, assim como nas associações especializadas da área de administração. Ensaio também não é forma facilitada de produção científica, em que é exigida apenas a razão do escritor, a partir da escolha do tema. [...] O ensaísta é antes de tudo experimentador e não reprodutor de conhecimento ou produto de reflexões presas à formalidade do método. Por meio do ensaio, a administração deve possibilitar um vir-a-ser, ou seja, elo entre o conhecimento existente e novo, baseados na originalidade. Em áreas como a administração esse processo é visto com desconfiança; para leitores cujas consciências já foram dominadas pelo método tradicional de fazer ciência esta forma de conhecimento é vista com preconceito. O fato é que a realização de um ensaio, em muitas situações, exige mais esforços do que o método científico de fazer ciência, visto que, sem as devidas caracterizações descritas anteriormente, não se pode atribuir a qualidade de ensaio a um conjunto de conceitos, teorias, argumentos etc.

Sobre o uso do ensaio na área de Administração, Bertero (2011, p. 340) postula que:

$\mathrm{Na}$ área de administração muitas contribuições na área tiveram a forma de ensaios. Lembremos autores como Peter Drucker, cuja obra é ensaística. O homem considerado até hoje o pai do management fugiu inteiramente à tradição da educação em administração norte-americana. Oriundo da Áustria, e pertencendo a uma geração que ainda não necessitava de titulação propiciada por mestrados e doutorados, teve uma produção que nunca se dirigiu aos periódicos considerados científicos da área. Contribuições originais de Drucker para a administração, como o conceito de Management by objectives (MBO), organizações intensivas em conhecimento knowledge 
intensive organizations, o trabalhador do conhecimento (knowledge worker), foram todos conceitos e ideias desenvolvidos e comunicados sob a forma de ensaios. Se tomarmos ainda o conhecido artigo de James March (1991), em que faz a distinção entre exploration e exploitation e seu conhecido conceito de garbage can (Cohen \& March, 1972), encontramo-nos também diante de ideias que fizeram avançar a área e que foram produzidos na forma de ensaios. Se nos voltamos para a área de estratégia empresarial, constataremos que o que hoje se conhece como Resource Based View (RBV) foi o resultado de uma série de ensaios, a começar pelo clássico artigo de Coase (1937) sobre a teoria da firma.

Bertero (2011) aponta que os três volumes do livro Handbook de Estudos Organizacionais (CLEGG; HARDY; NORD, 2006) são compostos por capítulos que têm a forma de ensaios teóricos, pois todos implicam revisão da literatura, não repetem o que foi dito pelos autores, mas procuram apresentar o conhecimento acumulado, articulando-o com frequência sob nova luz. Além disso, são feitas críticas e abertas perspectivas para caminhos futuros, sugerindo eliminação de algumas tendências e ênfase em outras pouco exploradas ou ainda por explorar.

Meneghetti (2011b) refere que a publicação do ensaio exige sensibilidade por parte do periódico, assim, considerando que, nos tempos atuais, os espaços para publicações estão cada vez mais fechados e restritos a formas tradicionais de fazer ciência.

No ensaio, o conteúdo influencia mais que a forma (formatação, sistematização dos tópicos, sequência dos itens, forma de exposição das ideias, etapas, etc.). Isso, no entanto, não implica total descaso ou despreocupação com a forma, pois esta afeta o conteúdo, tal como o tamanho e as características físicas de um formigueiro, que afetam o que acontece no seu interior (MENEGHETTI, 2011a). Por sua vez, Michel (2015) salienta as partes componentes do ensaio, como sendo: a introdução, o desenvolvimento e a conclusão. A estrutura proposta por Michel (2015) também não se trata de uma fórmula engessada, mas de uma orientação com o propósito de evidenciar o encadeamento lógico dos argumentos utilizados na defesa das proposições. 


\section{CONSIDERAÇÕES FINAIS}

Iniciou-se este trabalho com a proposta de caracterizar quatro tipos de textos científicos utilizados na área de Administração, Ciências Contábeis e Turismo, no Brasil, que são a pesquisa bibliográfica, a pesquisa bibliométrica, o artigo de revisão e o ensaio teórico. O processo de caracterização intencionou a identificação do que são, qual o propósito de cada um e que formas assumem esses tipos de comunicação científica.

Após a busca de conceitos em livros, revistas e outros textos científicos, evidenciaram-se não só algumas características comuns a mais de um tipo de texto, mas, também, características que esclarecem porque esses textos são considerados tipos diferentes de comunicação científica.

A pesquisa bibliográfica e o artigo de revisão compartilham de característica de busca de referencial bibliográfico em diversas fontes. Porém foi evidenciado que os autores compartilham da ideia de que o artigo de revisão necessita de um procedimento sistematizado de coleta de dados, enquanto que a pesquisa bibliográfica é aberta. Também ficou evidente a reflexão dos autores de que o artigo de revisão precisa ter uma questão de pesquisa bem-definida, que necessita apresentar uma resposta ao final de seu relato, enquanto a pesquisa bibliográfica pode ser usada como um meio para explorar o conhecimento acerca de determinado tema, sem, contudo, apresentar uma conclusão.

A literatura consultada aponta, quanto à forma, que a pesquisa bibliográfica pode ser reportada tanto como uma pesquisa em si quanto como um capítulo dentro de uma tese ou dissertação, enquanto que, ao artigo de revisão, resta apenas a primeira opção. $\mathrm{O}$ artigo de revisão pode, portanto, assumir a estrutura de um artigo empírico de cinco seções, quais sejam: introdução, fundamentação, metodologia, resultados e conclusão.

Acerca da pesquisa bibliométrica, bem pouco foi encontrado nos tradicionais livros-texto de metodologia, embora o volume de artigos ditos bibliométricos nas bases de dados, como Scielo e Spell, não seja desprezível. A característica de pesquisa bibliométrica, que a diferencia da pesquisa bibliográfica e do artigo de revisão, é o processo de mensuração, que pode 
abranger dimensões como número de autores, número de artigos, número de citações, número de coautorias, número de revistas, número de temas, frequência de cooperação de grupos, instituições ou países e obediência às leis de bibliometria. No entanto a ausência do processo de mensuração descaracteriza a classificação como pesquisa bibliométrica. A literatura apontou que os artigos bibliométricos também assumem a forma de artigos empíricos, compostos por cinco seções, analogamente ao que ocorre com os artigos de revisão.

Por sua vez, o ensaio teórico, aparentemente, é aquele que mais se diferencia dos outros três tipos de textos aqui caracterizados, tanto em conteúdo quanto em forma. $\mathrm{O}$ ensaio não é avaliado pela sua abrangência de cobertura, como a pesquisa bibliográfica e o artigo de revisão; nem pelo rigor dos processos quantitativos e evidências empíricas, como a pesquisa bibliométrica, mas, sim, pela sua originalidade e pelo ineditismo.

Os autores consultados afirmam que o ensaio teórico transcende a revisão crítica de resultados de trabalhos alheios, mas serve para que o ensaísta exponha questões críticas e reflexivas, que podem tangenciar as teorias, as evidências empíricas ou apenas a ampla experiência do ensaísta acerca do tema sobre o qual ensaia. A literatura aponta, ainda, que o mérito do ensaio encontra-se não apenas na proposição, mas, também, no ensaísta e no leitor, que precisam estar abertos a conhecimentos não derivados dentro do paradigma positivista.

O ensaio, segundo alguns autores, apresenta-se amorfo. No entanto uma das autoras consultadas nesta pesquisa sugere que ele possua, pelo menos, a introdução, o desenvolvimento e a conclusão.

Sugere-se, assim, para pesquisas futuras, a coleta de dados empíricos a fim de verificar se a síntese de conceitos oriundos da literatura de livros-texto de metodologia aqui exposta dá conta da prática dos autores de Administração, Ciências Contábeis e Turismo, segundo as comunicações científicas apresentadas em anais de eventos e publicadas por periódicos. 


\section{REFERÊNCIAS}

ALVES-MAZZOTTI, A. J. Usos e abusos dos estudos de caso. Cadernos de Pesquisa, São Paulo, v. 36, n. 129, p. 637-651, 2006. DOI: 10.1590/S0100-15742006000300007

AMERICAN PSYCHIATRIC ASSOCIATION. Manual de publicação da APA: American Psychological Association. Tradução: Daniel Bueno. 6.ed. Porto Alegre: Penso, 2012.

ANDRADE, M. M. de. Introdução à metodologia do trabalho científico: elaboração de trabalhos na graduação. 10.ed. São Paulo: Atlas, 2010.

ARAGÃO, I. R. B. N.; OLIVEIRA, J. R. S.; LIMA, G. A. S. F. Ressonância de Artigos e Fator de Impacto de Periódicos Brasileiros de Contabilidade. Revista de Educação e Pesquisa em Contabilidade (REPeC), Brasília, v. 8, n. 1, p. 5-21, jan./mar. 2014. DOI: 10.17524/repec. v8i1.1011

BERTERO, C. O. Réplica 2 - o que é um ensaio teórico? Réplica a Francis Kanashiro Meneghetti. Revista Administração Contemporânea, Rio de Janeiro, v. 15, n. 2, p. 338-342, abr. 2011. DOI: $10.1590 /$ S1415-65552011000200012

BIBLIOTECA VIRTUAL UNIVERSITÁRIA, 2017. Disponível em: <http:/ / pergamum. unisul.br/pergamum/biblioteca_s/php/login_usu.php?flag=index.php. > Acesso em: 26 out. 2017.

BOTELHO, L. L. R.; CUNHA, C. C. de A.; MACEDO, M. O método da revisão integrativa nos estudos organizacionais. Gestão e Sociedade, Belo Horizonte, v. 5, n. 11, p. 121-136, maio-ago. 2011. DOI: 10.21171 /ges.v5i11.1220

CAMPOS, O. V.; CUNHA, J. V. A. da; BARBOSA NETO, J. E. Estudo de caso, realmente são? Revista de Contabilidade e Controladoria, Curitiba, v. 7, n. 2, p. 61-76, maio/ago. 2015. DOI: $10.5380 /$ rcc.v7i2.35995

CESAR, A. M. R; ANTUNES, M. T. P.; VIDAL, P. G. Método do estudo de caso em pesquisas da área de contabilidade: uma comparação do seu rigor metodológico em publicações nacionais e internacionais. Revista de Informação Contábil, Recife, v. 4, n. 4, p. 42-64, out./dez. 2010.

CLEGG, S.; HARDY, C.; NORD, W. R. Handbook de estudos organizacionais. São Paulo: Atlas, 1999-2004.

ENANPAD. Apresentação. Disponível em: < http://www.anpad.org.br/ anpad/ eventos. ph p?cod_evento $=1>$. Acesso em: 27 set. 2017.

ENSSLIN, L. et al. ProKnow-C, knowledge development process-constructivist. Processo técnico com patente de registro pendente junto ao INPI.uma revista? Brasil, v. 10, n. 4, p. 2015, 2010.

FERENHOF, H. A.; FERNANDES, R. F. Desmistificando a revisão de literatura como base para redação científica: método SFF. Revista ACB, São José, v. 21, n. 3, p. 550-563, ago./nov., 2016. 
GIL, A. C. Como elaborar projetos de pesquisa. 6. ed. São Paulo: Atlas, 2017.

MARTINS, G. de A.; THEÓPHILO, C. R. Metodologia da investigação científica para ciências sociais aplicadas. 3. ed. São Paulo: Atlas, 2016.

MENEGHETTI, F. K. O que é um ensaio-teórico? Revista Administração Contemporânea, Rio de Janeiro, v. 15, n. 2, p. 320-332, abr. 2011a. DOI: 10.1590/S141565552011000200010

MENEGHETTI, F. K. Tréplica - o que é um ensaio-teórico? Tréplica à professora Kazue Saito Monteiro de Barros e ao professor Carlos Osmar Bertero. Revista Administração Contemporânea, Rio de Janeiro, v. 15, n. 2, p. 343-348, abr. 2011b. DOI: 10.1590/S141565552011000200013

MICHEL, M. H. Metodologia e pesquisa cientifica em ciências sociais: um guia prático para acompanhamento da disciplina e elaboração de trabalhos monográficos. 3. ed. São Paulo: Atlas, 2015.

MINHA BIBLIOTECA. Disponível em: < https:/ / pergamum.ufsc.br/pergamum/biblio teca_s $/$ php $/$ login_usu.php?flag $=$ minhabiblioteca_redirect.php $>$. Acesso em: 26 out. 2017.

NOGUEIRA, S. Ciência Proibida: As experiências científicas mais perigosas, assustadoras e cruéis já realizadas. São Paulo: Abril, 2015.

OKUBO, Y. Bibliometric Indicators and Analysis of Research Systems: Methods and Examples. OECD Science, Technology and Industry Working Papers, Paris, p. 1-70, jan./jun. 1997.

OLIVEIRA, M.; MAÇADA, A. C. G.; GOLDONI, V. Forças e fraquezas na aplicação do estudo de caso na área de sistemas de informação. REGE Revista de Gestão, São Paulo, v. 16, n. 1, p. 33-49, jan./mar. 2009. DOI: 10.5700/issn.2177-8736.rege.2009.36660

PACKER, A. SciELO Citation Index no Web of Science. 2014. Disponível em: http:/ / blog. scielo.org/blog/2014/02 / 28/scielo-citation-index-no-web-of-science/. Acesso em: 20 ago. 2017.

POZZEBON, M.; FREITAS, H. M. R. Pela aplicabilidade - com um maior rigor científico - dos estudos de caso em sistemas de informação. Revista de Administração Contemporânea, Rio de Janeiro, v. 2, n. 2, p. 143-170, maio/ago. 1998. DOI: 10.1590/S141565551998000200009

PROCIANOY, E. Metanálise. In: ALVES, M. R. (Org.). Metodologia científica. 3. ed. Rio de Janeiro: Cultura Médica: Guanabara, 2013.

ROTHER, E. T. Revisão sistemática X revisão narrativa. Acta paulista de enfermagem, São Paulo, v. 20, n. 2, p. v-vi, jun. 2007. DOI: 10.1590/S0103-21002007000200001

SCIELO. Pesquisa artigos. Disponível em: <http://www.scielo.org/php/index.php>. Acesso em: 26 out. 2017. 


\section{JACIR LEONIR CASAGRANDE}

SEMEAD. Apresentação e publicação dos trabalhos. Disponível em: <http: / semead.com. br/20/trabalhos/apresentacao-dos-trabalhos/ >. Acesso em: 27 set. 2017.

SOARES, S. V. Diga-me quantos te citam, e eu te direi quem és - Estudo sobre as citações no âmbito da pesquisa contábil brasileira. 2017. 281p. Tese (Doutorado em Controladoria e Contabilidade) - Programa de Pós-Graduação em Controladoria e Contabilidade, Faculdade de Economia, Administração e Contabilidade, Universidade de São Paulo, São Paulo, 2017.

SOARES, S. V.; CASA NOVA, S. P. de C. "Diga-me quantos te citam, e eu te direi quem és": Estudo sobre as citações no âmbito da pesquisa contábil brasileira. In: SEMINÁRIOS EM ADMINISTRAÇÃO - SEMEAD, 20, 2017, São Paulo. Anais... São Paulo: FEA/USP, 2017.

SOARES, S. V.; CASA NOVA, S. P. de C. O Qualis reflete o impacto dos artigos de Revistas Brasileiras de Contabilidade?. Revista de Gestão, Finanças e Contabilidade, Salvador, v. 6, n. 3, p. 6-23, set./ dez. 2016.

SOARES, S. V.; LIMA FILHO, R. N. É o Google Acadêmico uma opção plausível para análise de citações dos periódicos brasileiros de Contabilidade. In: COLÓQUIO INTERNACIONAL DE GESTÃO UNIVERSITÁRIA - CIGU, 17, 2017, Mar del Plata. Anais... Mar del Plata: INPEAU, 2017.

SOUZA, J. V. de; ENSSLIN, S. R.; ENSSLIN, L. Panorama dos periódicos vinculados à área contábil quanto ao reconhecimento da sociedade científica. In: CONGRESSO USP DE CONTROLADORIA E CONTABILIDADE, 12, 2012, São Paulo. Anais... São Paulo: FEA/USP, 2012.

SPELL. Pesquisa avançada. Disponível em: <http:/ / www.spell.org.br/>. Acesso em: 26 out. 2017.

SPLITTER, K.; ROSA, C. A. da; BORBA, J. A. Uma análise das características dos trabalhos "ditos" bibliométricos publicados no Enanpad entre 2000 e 2011. In: ENCONTRO DA ANPAD - ENANPAD, 36., 2012, Rio de Janeiro. Anais... Rio de Janeiro: Anpad, 2012.

VAZ, C. R.; MALDONADO, M. U. Revisão de Literatura Estruturada: Proposta do Modelo SYSMAP (Scientometric And Systematic Yielding Mapping Process). In: VAZ, C. R.; MALDONADO, M. U. (Org.). Aplicações de Bibliometria e Análise de Conteúdo em casos da Engenharia de Produção. Florianópolis: UFSC, 2017. Cap. 2., p. 21-42. 


\section{DADOS DOS AUTORES}

\section{SANDRO VIEIRA SOARES sandrovs@usp.br}

\section{Doutor em Contabilidade pela USP}

Instituição de vinculação: Universidade do Sul de Santa Catarina

Florianópolis/SC - Brasil

Áreas de interesse em pesquisa: Ensino e Metodologia de pesquisa em Administração e Contabilidade.

${ }^{\star}$ Rua Adolfo Melo, 34, $9^{\circ}$ andar Centro Florianópolis/SC 88015-090

\section{ICARO ROBERTO AZEVEDO PICOLLI icaropicolli@gmail.com}

\section{Mestre em Administração pela UNISUL}

Instituição de vinculação: Universidade do Sul de Santa Catarina

Florianópolis/SC - Brasil

Áreas de interesse em pesquisa: Administração Estratégica.

\section{JACIR LEONIR CASAGRANDE jacir.casagrande@unisul.br}

\section{Doutor em Engenharia de Produção pela UFSC}

Instituição de vinculação: Universidade do Sul de Santa Catarina

Florianópolis/SC - Brasil

Áreas de interesse em pesquisa: Inovação e Sociedade. 